Revista de la red interuniversitaria de estudios sobre las literaturas rioplatenses contemporáneas en Francia

$18 \mid 2018$

El río y la ciudad

\title{
“Añoro patria": Jorge Luis Borges y Xul Solar
}

\section{Sylvia Molloy}

\section{OpenEdition}

\section{Journals}

Edición electrónica

URL: http://journals.openedition.org/lirico/5603

DOI: $10.4000 /$ lirico.5603

ISSN: 2262-8339

Editor

Réseau interuniversitaire d'étude des littératures contemporaines du Río de la Plata

\section{Referencia electrónica}

Sylvia Molloy, «"Añoro patria": Jorge Luis Borges y Xul Solar », Cuadernos LIRICO [En línea], 18 | 2018,

Puesto en línea el 09 octubre 2018, consultado el 01 mayo 2019. URL : http:// journals.openedition.org/lirico/5603; DOI : 10.4000/lirico.5603

Este documento fue generado automáticamente el 1 mayo 2019.

\section{(c) (i) (9)}

Cuadernos LIRICO está distribuido bajo una Licencia Creative Commons Atribución-NoComercialSinDerivar 4.0 Internacional. 


\title{
"Añoro patria": Jorge Luis Borges y Xul Solar
}

\author{
Sylvia Molloy
}

Lo marginal es lo más bello. Borges, "Crítica del paisaje"

1 Para pensar el encuentro de la ciudad y el río elijo dos figuras que hicieron de la ciudad y el río, o más precisamente del margen, en más de un sentido del término, el espacio privilegiado de sus respectivas obras: Borges y Xul Solar. Y empiezo con el viaje a Europa de cada uno, viaje semejante al que emprenden muchos escritores y artistas latinoamericanos de la época para, como reza el cliché, "encontrarse". Viajes que obedecen a impulsos diversos se transforman, retrospectivamente, en viajes de formación, extendiéndose más de lo previsto, volviéndose en efecto períodos de aprendizaje. En 1910 Xul Solar decide viajar a Australia con un amigo, pero el viaje no se realiza. Dos años más tarde, cambiando de rumbo, parte imprevisiblemente para Europa. Desembarca en Londres, de allí pasa a Turín, deambula por varios países, se instala un tiempo en el norte de Italia, pasa tiempo en París, en Milán, en Munich. Toma contacto con, por un lado, estudiosos de lo oculto, como Aleister Crowley, y por otro con el futurismo y el expresionismo europeos; refuerza sus vínculos con Pettoruti, otro pintor argentino emigrado, por intermedio de quien es posible que haya conocido a Klee; participa en exposiciones y finalmente, en 1924, regresa a la Argentina. La estadía de Borges en Europa es más breve pero no menos movida. En 1914, a los quince años, emprende con su familia el tradicional viaje argentino a Europa, viaje que se prolonga a causa de la primera guerra mundial. Postergada la posibilidad del retorno, el viaje familiar se transforma en estadía pedagógica: los Borges también deambulan por Europa, llegan a Lisboa, viajan a París, pasan la guerra en Ginebra donde Borges cursa estudios, luego se mudan a España donde Borges entra en contacto con la vanguardia española, permanecen un tiempo en Palma de Mallorca y regresan finalmente a Buenos Aires en 1921.

2 He entrado en el detalle de estos desplazamientos para entender mejor ciertas posiciones -también podrían llamarse posturas- que aparecen en una y otra obra. Me interesa ver 
cómo -ya durante el viaje mismo en el caso de Xul, ya en vísperas del regreso en el caso de Borges- se van reformulando en sus respectivas obras nociones de patria, de extranjería, de pertenencia nacional y de espacio urbano: Tanto Xul como Borges van viendo lo que dejaron atrás -y muy especialmente la ciudad junto al río- con otra mirada, a la luz de los diversos futurismos que proponen las vanguardias europeas con las que han entrado en contacto. El Buenos Aires dejado atrás se irrealiza durante el viaje europeo y (como la Buenos Aires que visita Marcel Duchamp) deja casi de existir. Me interesa sobre todo ver cómo los respectivos regresos -el de Xul en 1924, cuando cuenta treinta y siete años; el de Borges en 1921, cuando cuenta veintidós-, y sus respectivas reinserciones en la ciudad de Buenos Aires, modifican esa mirada, alteran el paisaje mental que cada uno se había llevado y hacen que ambos reformulen un nuevo Buenos Aires, una nueva ciudad junto al río. La "lección" que resulta del viaje para ambos parece ser la esencial inestabilidad de ciertos conceptos tenidos por inamovibles, inestabilidad que lleva a un vaivén tanto formal como conceptual de los elementos que componen la ciudad junto al río y, sobre todo, a reformular la orilla que sirve de nexo entre los dos.

3 La ciudad y el río dejados atrás no encuentran formulación explícita en Borges durante su estadía europea ni quedan registrados como objeto de nostalgia, lo cual posiblemente se explique por su edad y su situación: el adolescente, aún inseguro literariamente, desdeña localismos a favor de una pose cosmopolita y procura encontrarse a sí mismo como europeo. No es el caso de Xul. Mayor que Borges, más seguro del lugar al que aspira como artista visual, también adopta una posición cosmopolita, pero es una posición que ya ha trabajado y, de hecho, lleva consigo desde su primera partida de Buenos Aires. Pienso en dos cuadros, Añoro patria (1922) y Despedida (1923), pintados muy poco antes de su regreso, que le permiten plasmar esa añoranza y volverla complejo instrumento estético y político. En Añoro patria se ve un barco cargado de cinco personas que se alejan de una orilla donde ronda un animal indefinido, quizá subtropical, como acaso también lo sean las esbeltas palmeras. Podría ser el Chaco, tema ya de otro cuadro de Xul, también de 1922; o también podría ser el Tigre, que se volvería más tarde su otra orilla, su patria chica. El barco se está yendo, como parecerían indicar la posición de los remos, problematizando ya el título: ¿Cuándo y desde dónde se empieza a añorar? El barco se marcha pero está demasiado cerca de la costa a la que los remeros resueltamente dan la espalda: reman no para volver sino para alejarse. Pero uno, acaso el añorante que justifica el título, mira para atrás, hacia lo que presumimos es la patria, como también lo hace la bandera argentina en la popa. Parafraseando el verso de Octavio Paz: ¿Va o viene este barco? Además: ¿Qué es lo que se añora? ¿Una patria hacia la cual se regresa o una patria que se está dejando atrás y a la que la banderita parecería querer volver? Formulado desde la añoranza, desde la orilla, se diría que el cuadro celebra no tanto un impulso a regresar sino la indecisión. 


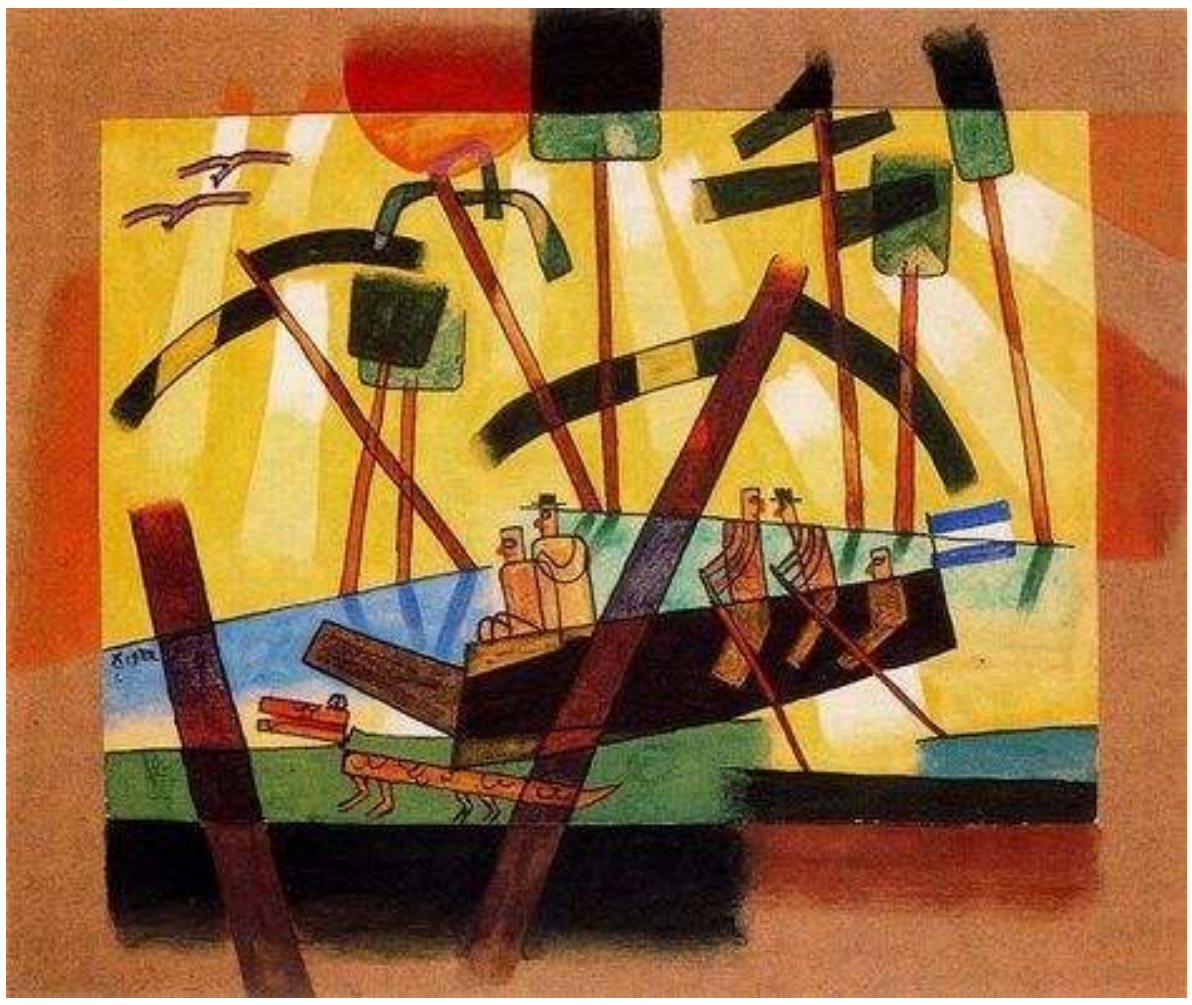

Figura 1: Xul Solar, Añoro patria

4 Miro otro cuadro, del año siguiente, Despedida, también pintado en Europa. Otra vez la orilla: de nuevo un barco con tres viajeros y, en la costa, un hombre que hace un gesto ambiguo hacia ellos. Por el vestido y el tocado, los viajeros parecen personajes precolombinos, frecuentes en el Xul de esa época para significar una América arcaica y una "vanguardia neocriolla"1. El hombrecito de la costa no tiene, en cambio, vestido nacional distintivo, se diría un joven moderno con traje de trabajo. Si se trata de la despedida de los viajeros, quienes como Xul estarían alejándose de América, los términos están invertidos; aquí parece ser la América autóctona que parte dejando solo al hombrecito. Además, saltan a la vista dos detalles: las velas infladas por el viento de nuevo indican contradicción: una parece señalar que el barquito está llegando a la costa, la otra que se aleja. Y el gesto del hombrecito de la costa es igualmente ambiguo: ¿está despidiendo a los viajeros o acaba de darles un empujón para que se vayan definitivamente? 


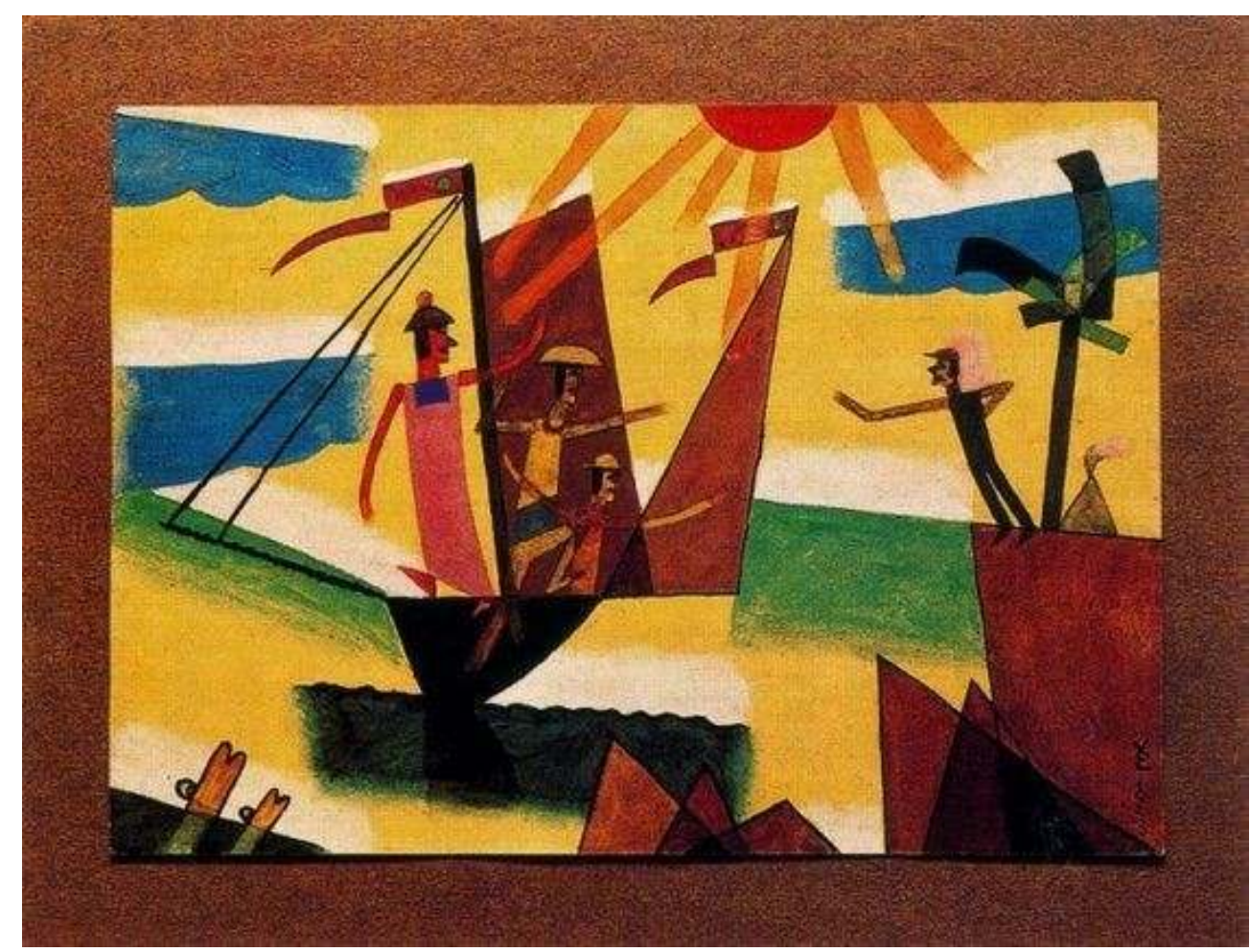

Figura 2: Xul Solar, Despedida.

5 Se me dirá que esta lógica simplista y reductiva poco tiene que ver con Xul y que el viento, en su obra, como para otros el espíritu, sopla donde quiere. No lo niego. Pero propongo que la ligereza de Xul, el humor y el desparpajo con que desubica a sus viajeros y por ende a sus espectadores, son signos del espíritu desestabilizador de su obra, en particular cuando se trata de viajes, y muy en particular cuando se representa lo nacional -la patria que se añora- cifrado en un inestable paisaje fluvial. Porque, notablemente, en estos dos cuadros de Xul hay río pero no hay ciudad, solo hay orilla: la ciudad vendrá más tarde, cuando Xul regrese y se enfrente con una Buenos Aires a la que mira oblicuamente y que, muy rápido, modificará y reconstruirá en su pintura.

6 A diferencia de Xul, las primeras reflexiones de Borges sobre la descolocación y el consiguiente extrañamiento no se dan mientras está en Europa sino literalmente en el barco que lo lleva de vuelta a la Argentina. (Borges podría ser, sin demasiado esfuerzo, uno de los ambiguos viajeros que van y/o vienen en los barquitos de Xul). En la extensa correspondencia que mantiene durante la travesía con los amigos europeos que ha dejado atrás, sobre todo con Maurice Abramovicz y Jacobo Sureda, Borges se atribuye el papel de peregrino en su patria, sin duda para complacer a los corresponsales dejados atrás pero también, propongo, en beneficio propio. Insiste, por ejemplo, en su no argentinidad y hace alarde de extranjería: "Si uno no es griego o español, la única manera de tener un poco de cultura en los huesos es ser judío, como tú", escribe a Abramovicz. "O italiano o moro. (Los españoles somos medio moros, sobre todo los andaluces. Yo tengo antepasados de Córdoba y de Málaga)"2. Este distanciamiento con respecto a una subjetividad nacional permite al retornante postularse, aún antes de su llegada, como disidente, como el que "no se encuentra" en la casa de donde se marchó. "La vuelta a Buenos Aires me entristece -iy cuánto!", escribe al mismo destinatario; "Voy juntando por aquí y por allá informaciones sobre ese extraño país"3. Ese extraño país sobre el cual Borges debe documentarse -la patria, la ciudad, la orilla, vueltas desasosegantes cuando no siniestras- 
aparece también en las cartas a su otro amigo europeo, Jacobo Sureda, ya como paisaje totalmente ajeno que se anticipa, ya como lugar de afincamiento provisorio, como una escala más antes del regreso a Europa:

"Nos hemos anclado en Buenos Aires en un barrio geometral, serio y sosegado.

(Casas de un piso, filas de plátanos otoñales que cubren sus ramas pobres con vendas de sol, tranvías, pentagramas telefónicos rayando el flaco y aguachirle azul del cielo, risas de niños en la calle...) Esto no nos entusiasma gran cosa y, en cuanto hayamos ultimado una serie de asuntos que nos molestan, volveremos al viejo continente, más nuevo que éste, que esta América donde todo parece flojo y marchito. Volveremos tal vez antes de un año4.

7 "Esto", "este extraño país", para hablar de la ciudad a la que se vuelve: la postura en estas cartas, escritas o bien a bordo del barco que lo lleva a Buenos Aires o bien recién llegado, recuerda la de Gardel en uno de sus últimos films, El día que me quieras. En una escena en la cubierta del barco, Gardel canta uno de sus tangos más famosos, Volver, festejando la ciudad a la que regresa en una verdadera epifanía de reconocimiento. Pero lo que llama la atención en el film es que Gardel canta no en la proa, mirando hacia Buenos Aires, sino en la popa. Si bien ya en el río de la Plata y cerca de la ciudad, le da la espalda: no mira el paisaje que lo espera sino el que ha dejado atrás. Este gesto físico de dar la espalda al "hogar", parecido a la contradictoria direccionalidad de los barcos en los cuadros de Xul que he mencionado, evidencia -como no hubiera podido hacerlo ninguna otra imagen- el comienzo de una fértil desorientación para los dos retornantes.

Como Borges, Xul recompone, en la obra que produce a su regreso, la intersección ciudad y río. En un primer momento, Xul llena el no man's land de la orilla con una edificación urbana febril y algo disparatada. Pienso en Puerto azul, en Cinco casas, en Fecha patria, en Jol

En casi todos estos cuadros (compuestos entre 1922 y 1927) se ve el río por detrás como elemento estable, vasto, sin "vereda de enfrente", como diría más tarde Borges hablando de las afueras de la ciudad. Se recalca la verticalidad de la ciudad, su desorden, su falta de equilibro: los edificios se retuercen, los seres humanos parecen frenéticos insectos. Además, a diferencia de Borges, en Xul hay más de una ciudad. Por un lado, la magnífica urbe de Ciudad Lagui ${ }^{5}$; por el otro, el enjambre de casas encimadas -descolocadas, se podría decir- en Barrio, o la ciudad borrada por el puerto en Puerto Azul. Por fin, la siempre cambiante ciudad es capaz de movimiento: en Vuel Villa, literalmente, levanta vuelo por sobre el río y se va a otra parte. 


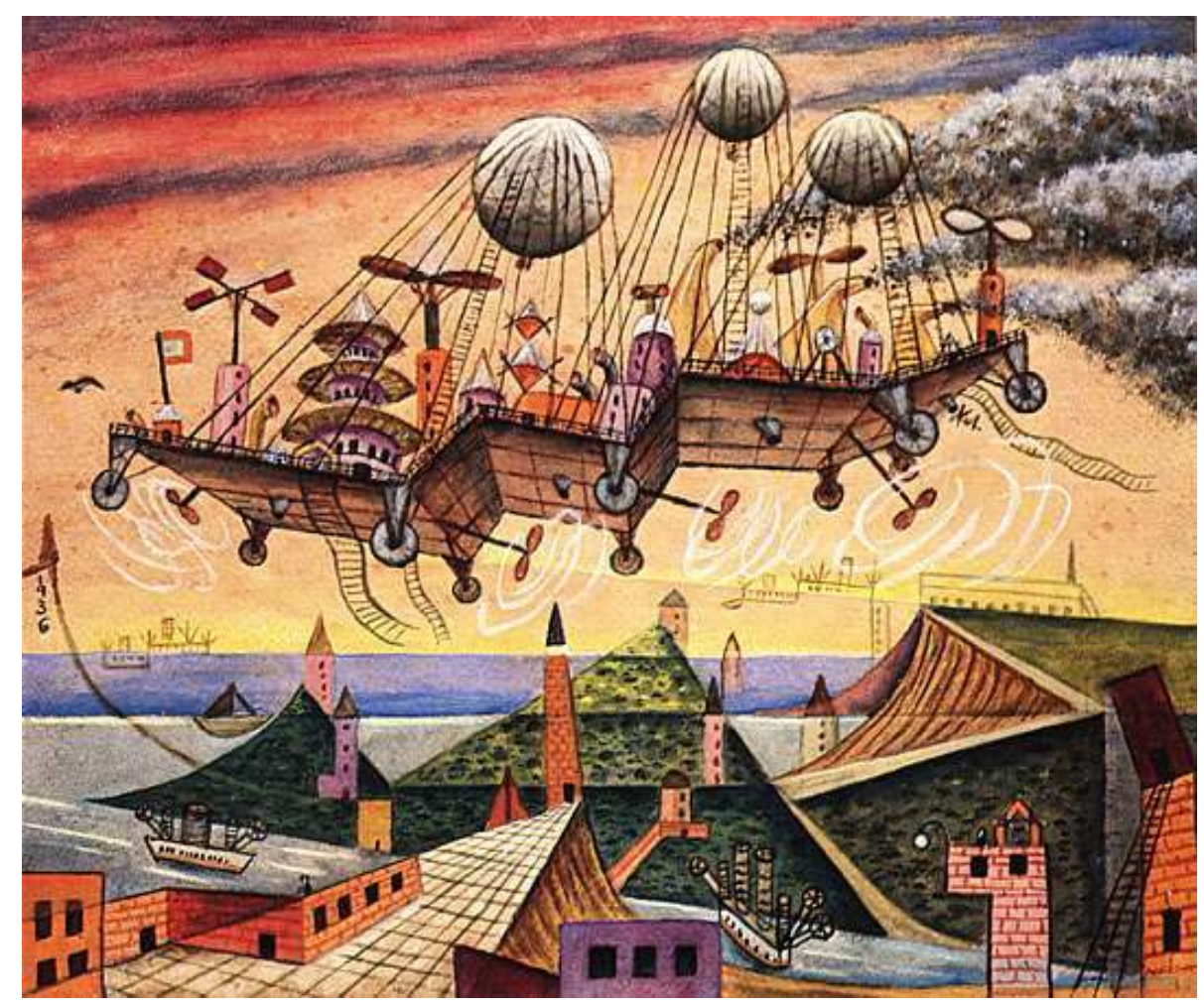

Figura 3: Xul Solar, Vuel Villa

10 Uno de los avatares de esta "otra parte" para Xul es el Delta del Paraná, lugar que privilegia en los años 50 como espacio de representación y como sitio donde aposentarse. Como antes la de Borges, quien no soporta la centralidad, la ciudad de Xul se traslada al suburbio y a un lugar donde el río -otro río, el Paraná- cumple una función más orgánica: ya no es entorno de la ciudad moderna sino elemento estructural, soporte de la vivienda misma.

11 En cambio Borges, en lugar de llenar y complicar el centro urbano como Xul y abrirlo a la extranjería, lo deja de lado. En primer lugar, escamotea la presencia del río: lo separa de la ciudad, como lo aclara, prepotentemente, el hablante de "Fundación mítica de Buenos Aires". Así a la pregunta inicial:

¿Y fue por este río de sueñera y de barro

que las proas vinieron a fundarme la patria?

12 Y a la suposición que sigue, de que la primera versión de la ciudad fue al borde del Riachuelo, responde tajantemente:

pero son embelecos fraguados en la Boca.

Fue una manzana entera y en mi barrio: en Palermo.

Una manzana entera pero en mitá del campo.

Borges describe el río que bordea la ciudad como "él agua cuadrada de la dársena" y la Boca, donde se fraguan los embelecos fluviales, es blanco perpetuo de desdén. "Decimos con nebulosidad las orillas, pero son una cosa las de la Boca, orillas con marinerío, orillas del agua, y otra cosa las que por Urquiza se alargan: orillas de la tierra, orillas de la nochecita y de la llanura"6. Para recuperar la orilla y volverla fuente de creación Borges necesita trasladarla, reinventarla; de hecho, alejarla del río mismo. De éste persiste la noción de orilla, tan importante para Borges, pero ahora se trata de una orilla urbana, entre la ciudad y el campo. 
Propongo que en ambos casos, el de Borges y el de Xul, el retorno a la ciudad con su río es un desafío fecundo. Lejos de regresar como, pongamos por caso, Ricardo Güiraldes, empeñado en encarnar sin cuestionamientos un nativismo que se traduce a veces en imágenes deplorables -así el protagonista de su novela Raucho, quien se desploma "crucificado de calma en su pampa de siempre"-, Borges y Xul no buscan la asimilación sino la diferencia, ese estar entre desasosegante. Si recurren a lo nacional, como lo hacen, con distancia, tantos latinoamericanos de los años veinte (sin ir más lejos los grupos de Proa y Martín Fierro), lo hacen como desterrados natos, para usar una expresión del propio Borges, desde una orilla a la vez conceptual y real en Xul y más conceptual que real en el caso de Borges. Cultivan nacionalismos fluidos que desestabilizan ideologías vigentes, proponen lenguajes nuevos (el neocriollo de Xul, la oralidad transcripta del primer Borges) y sobre todo geografías fantasiosas y faux-naif que pueblan con banderitas argentinas (los cuadros de Xul), con casitas de arrabal con "balaustraditas" y sin vereda de enfrente, o con barquitos que avanzan por el "río de sueñera y de barro" para "fundarme la patria" en Borges.

Pero esa graciosa simbología patriótica, falsamente ingenua, dista de significar sólo la patria chica y reclama un afuera de lo nacional que lo complete. Y, acaso, que lo cuestione: así, las banderitas argentinas de Xul se complementan con banderitas brasileñas, italianas, o meramente inventadas, en plena fiesta cosmopolita. Borges a su vez extrapola citas europeas, referencias a Robert Browning, por ejemplo, como otras tantas banderitas, para hablar del muy criollo Evaristo Carriego. Se trata de lo que Beatriz Sarlo llama con acierto un "universalismo nacional" y una "cultura de mezcla"; igualmente podría hablarse de un criollismo cosmopolita, o un cosmopolitismo de las orillas $^{7}$. Criollismo que se toma y no se toma en serio, recuerda por momentos los dislates de otro desterrado, Jules Supervielle, quien también en 1923, en L'Homme de la Pampa, cultiva lo que años más tarde se reconoce como criollismo de ruptura8 ${ }^{8}$.

Lo que difiere, sin duda, más allá del medio que utiliza cada uno, es la imagen que uno u otro busca inventar del espacio al que vuelve y los recursos a que acude para significar un "retorno al hogar" que dista de ser simple. Si comparamos una y otra propuesta de patria (recurro al término ya que los dos lo utilizan) a través de la representación que cada uno procura de la ciudad, meta de ambos regresos, las diferencias son evidentes; no así, propongo, el espíritu que anima a cada uno. Xul recurre resueltamente a la visión premonitora, propone lo que Jason Wilson llama "un espacio cosmopolita irreconocible" que trasciende la Buenos Aires modestamente moderna de los años veinte y treinta. Abarrotada de torres y rascacielos, como Ciudad Lagui, recuerda la Metrópolis de Fritz Lang pero sin la amenazante negrura. Xul agiganta, internacionaliza, practica una suerte de monstruosidad lúdica; Borges, no menos inventor, recurre en cambio a la invención por medio del anacronismo y el deliberado empobrecimiento. Se vuelve -en la selección de íconos, en el lenguaje (piénsese en los diminutivos), en la ortografía- casi paródicamente local. Transcribe la oralidad callejera -oralidá, habría escrito en esa primera época- como un extranjero que citara una lengua recién aprendida.

$17 \mathrm{Si}$, como propone Beatriz Sarlo, el Buenos Aires de Xul es un rompecabezas ${ }^{10}$, en Borges es más bien una deriva. Borges resiente la verticalidad de la ciudad, verticalidad céntrica que, pese a sus negaciones, ya había comenzado antes de que se marchara a Europa: la Galería Güemes es de 1915 y el Pasaje Barolo, de 1923, está en plena construcción cuando Borges vuelve a Buenos Aires. En cambio, anacrónicamente, celebra la chatura: "A despecho de la humillación transitoria que logran infligirnos algunos eminentes edificios, 
la visión total de Buenos Aires nada tiene de enhiesta. No es Buenos Aires una ciudad izada y ascendente [...]. Es más bien un trasunto de la planicie que la ciñe"11. Borges da la espalda a ese centro y funda su Buenos Aires, de casas bajas, al borde de esta ciudad en vías de modernización. Es esa la orilla de Borges, el espacio que separa la ciudad del campo donde, como en el río de la Plata, no hay "vereda de enfrente"; un arrabal siempre listo a ser desplazado más allá, para ser siempre orilla: " $¡ Y$ hasta esa patria chica [...] se está volviendo centro y he de buscarla en Villa Alvear!". Como la costa en los primeros cuadros de Xul, es lugar disponible, donde Borges se inicia como escritor.

Ni Borges ni Xul Solar celebran un retorno reconfortante ni una restauración feliz. Pero justamente no se trata de un complaciente reintegro sino de una desubicación fundamental que es motor de creación para cada uno. Xul imagina una ciudad y un río hacia el futuro, Borges aleja la ciudad del río, traduce la noción de orilla, y la imagina para adentro y hacia el pasado: los dos crean un no-man's-land urbano, generador de un arte nuevo. "Diferenciémonos" proponía Xul como lema en $1924^{12}$. No cabe duda de que tanto él como Borges lograron ese cometido.

\section{NOTAS}

1. A diferencia de Borges, para quien lo nacional se formula (y se cuestiona) en términos estrictamente rioplatenses.

2. Jorge Luis Borges, Cartas del fervor. Correspondencia con Maurice Abramowicz y Jacobo Sureda (1919-1928), prólogo de Joaquín Marco, notas de Carlos García, edición al cuidado de Cristóbal Pera, Barcelona, Galaxia Gutenberg-Círculo de Editores-Emecé, 1999, p. 130. Énfasis añadido.

3. Ibidem, p. 134.

4. Ibidem, p. 198.

5. Esta obra se utiliza para ilustrar este número de Cuadernos LIRICO; también es mencionada por Mercedes Di Virgilio. Ver, en este número: "Buenos Aires y la ribera: Continuidades y cambios de una relación esquiva".

6. Jorge Luis Borges, Cartas del fervor, op. cit., p. 252.

7. "A lo largo de estas décadas, tanto para Borges como para Xul, el criollismo y el cosmopolitismo no se oponían en contradicción absoluta. Por el contrario, la mezcla misma de los dos conceptos constituía una solución original a la busca de un perfil cultural en un país donde los distintos estratos hereditarios (criollo-hispánico o europeo-occidental) eran objeto de rápidas transformaciones bajo la presión perturbadora de otras tradiciones". Beatriz Sarlo, "Fantastic Invention and Cultural Nationality: The Case of Xul Solar", en David Elliot (ed.), Argentina 1920-1994. Art from Argentina, Oxford, Museum of Modern Art, 1994, p. 34-39. Traducción mía.

8. Ver Damián Tabarovsky, “Intervenciones de un editor”, Página 12, 4 de diciembre, 2007.

9. Jason Wilson, "The Mutating City: Buenos Aires and the Avant-garde, Borges, Xul Solar, and Marechal", Hispanic Research Journal, 4:3, Londres, Taylor \& Francis, 2003, p. 251.

10. Beatriz Sarlo, Una modernidad periférica: Buenos Aires 1920 y 1930, Buenos Aires, Nueva Visión, 1988 , p. 15.

11. Jorge Luis Borges, Inquisiciones, Buenos Aires, Proa, 1925, p. 80. 
12. Citado en Jorge López Anaya, Xul Solar, una utopía espiritualista, Buenos Aires, Fundación Pan Klub-Museo Xul Solar, 2002, p. 25.

\section{RESÚMENES}

En este artículo se estudia el encuentro entre la ciudad y el río a partir de algunas obras de Jorge Luis Borges y Xul Solar. Se considera este tema, en particular, desde la perspectiva del "regreso" de ambos artistas a Buenos Aires luego de la experiencia europea a principios de los años 20. Respondiendo con ironía y lucidez a los postulados de los nacionalismos y modernismos locales, Borges y Xul Solar, cada uno a su manera, coinciden en redefinir la noción de "orilla". A partir de esta desubicación dinámica cada uno construye su diferencia.

L'article analyse la rencontre entre la ville et le fleuve à partir des ouvrages de Jorge Luis Borges et Xul Solar. Le travail a été réalisé à partir de la perspective du " retour » des deux artistes à Buenos Aires après leur expérience européenne au début des années 1920. Jorge Luis Borges et Xul Solar répondent aux postulats des nationalismes et des modernismes locaux avec ironie et lucidité. Les deux artistes, chacun à sa façon, redéfinissent la notion de " rivage ». Ils construisent leur différence particulière à partir de cette délocalisation dynamique

In this article, the author analyzes the encounter between the city and the river through some of the works of Jorge Luis Borges and Xul Solar, notably from the perspective of both artists' "return" to Buenos Aires after their European experience, at the beginning of the 1920s. Responding with irony and lucidity to the premises of the local nationalisms and modernisms, Borges and Solar coincide, each one in his own way, in redefining the notion of "riverside". From this dynamic displacement, each one builds his own character.

\section{ÍNDICE}

Keywords: Xul Solar, Jorge Luis Borges, riverside, return, Buenos Aires

Mots-clés: Xul Solar, Jorge Luís Borges, rivage, retour, Buenos Aires

Palabras claves: Xul Solar, Jorge Luís Borges, orilla, regreso, Buenos Aires

\section{AUTOR}

\section{SYLVIA MOLLOY}

New York University

sylvia.molloy@nyu.edu 